Jern, A. (2018). People are intuitive economists under the right conditions. Behavioral and Brain Sciences, 41. [Commentary on Boyer \& Petersen (2018).]

\title{
People are intuitive economists under the right conditions
}

\author{
Alan Jern \\ Department of Humanities and Social Sciences \\ Rose-Hulman Institute of Technology
}

\begin{abstract}
Boyer and Petersen argue that a "rudimentary exchange psychology" is responsible for many of people's folk-economic beliefs that are at odds with the consensus views of economists. However, they focus primarily on macroeconomic beliefs. I argue that the same rudimentary exchange psychology could be expected to produce fairly accurate microeconomic intuitions. Existing evidence supports this prediction.
\end{abstract}

Boyer and Petersen make a compelling case that people's folk-economic beliefs are primarily shaped by what they call a "rudimentary exchange psychology" that would have been adaptive in the small hunter-gatherer groups of our ancestors. They show that some of the intuitions based on this psychology can explain why many people today share certain folk-economic beliefs, many of which do not align with the consensus views of economists (e.g. Caplan, 2008). However, Boyer and Petersen focus primarily on folk-economic beliefs about macroeconomic issues - precisely the sorts of issues that our rudimentary exchange psychology is most poorly equipped to handle. On the other hand, many microeconomic judgments - like making predictions about other people's choices, or making inferences about people's preferences - are much closer to the sorts of judgments that our ancestors would have had to make in simple exchange economies. Boyer's and Petersen's account therefore makes an additional prediction that they do not discuss: that people will behave much more like intuitive economists when reasoning about other people's microeconomic choices. As I will show, existing evidence supports this prediction.

First, it should be acknowledged, as Boyer and Petersen do, that people certainly are not intuitive economists when it comes to making economic choices. The behavioral economics literature is full of examples of people deviating from the prescriptions of rational choice theory. To give just a few examples, people weigh losses more heavily than gains (Kahneman \& Tversky, 1979), ignore opportunity costs (Frederick, Novemsky, Wang, Dhar, \& Nowlis, 2009), and allow themselves to be influenced by sunk costs (Arkes \& Blumer.

Corresponding author: Alan Jern, Department of Humanities and Social Sciences, Rose-Hulman Institute of Technology, 5500 Wabash Ave, Terre Haute, IN 47803. E-mail: jern@rose-hulman.edu. 
1985; Thaler, 1999). These tendencies lead people to make poor choices involving their time and money.

However, people often think about other people's choices differently than their own choices. Whereas people's own choices are sometimes driven by emotion, which can bias people toward making impulsive and irrational decisions, people tend to be less emotional and more objective when reasoning about other people's choices. Trope and Liberman (2010) have shown that this is a domain-general phenomenon: as psychological distance increases (e.g., from choices someone is making for one's self to reasoning about someone else's choices), people tend to think more abstractly. The more abstractly people think about economic problems, the more they will tend to rely on intuitions rooted in their rudimentary exchange psychology. And for many microeconomic problems, these intuitions will lead people to make judgments that are in close alignment with how economists think. Evidence suggests this is true even if those judgments do not align with their own behavior.

For example, people's behavior in the two-player Ultimatum Game is often used as an example of irrational economic behavior. In the game, the first player offers a split of a sum of money between both players. The second player can either accept or reject the offer. If the second player rejects the offer, neither player receives any money. The economically rational thing for the second player to do is to accept any offer, but many people reject unfair offers (Thaler, 1988). However, Kim, Schnall, Yi, and White (2013) found that when subjects were asked to imagine they were playing on behalf of a stranger, thus placing some psychological distance between the subjects and their choices in the game, their acceptance rates increased for unfair offers, bringing their choices more in line with economic norms. As another example, Mazar, Amir, and Ariely (2008) performed an experiment in which subjects were given an opportunity to cheat on a task and were given different monetary incentives for cheating. They found that the amount subjects cheated did not vary with the incentive for cheating, contrary to the predictions of economists (e.g., Becker, 1968). The researchers also asked a separate group of subjects to predict the outcome of the experiment. This second group of subjects shared the intuitions of economists, expecting the first group of subjects to cheat more when the incentives for cheating were greater. Once again, people's intuitions about other people's choices were different than people's actual behavior, and those intuitions were aligned with economists' views.

Both of these examples involve predicting other people's choices. But people are also capable of making inferences about other people's characteristics, like their preferences, by observing the choices they make. To provide one such example from my own work, we (Jern, Lucas, \& Kemp, 2017) presented subjects with different hypothetical choices that other people had made between different bags of candy and asked subjects to order them by how strong of a preference the person making the choice had for red candy. We compared subjects' mean rankings of the choices to predictions generated by the logit model, a model commonly used by economists for learning consumers' preferences (McFadden, 1974, Train, 2009). We found a strong correlation between subjects' rankings and the rankings of the logit model, suggesting that people learn others' preferences in much the same way that the logit model does, and by extension, the way that many economists do.

Decades of empirical work and even casual observation point to the conclusion that people are not intuitive economists. Boyer and Petersen offer a theoretical argument for why this is the case. But, I have argued, their account can also explain why people may 
actually be quite astute intuitive economists under certain conditions. While it is true that modern markets are dramatically different from the exchange economies of huntergatherer societies, causing our rudimentary exchange psychology to produce some faulty macroeconomic intuitions, the act of choosing from a set of options has remained largely the same over time. It therefore stands to reason that people's microeconomic intuitions should be quite reasonable, and perhaps even consistent with prevailing economic norms.

\section{References}

Arkes, H. R., \& Blumer, C. (1985). The psychology of sunk cost. Organizational Behavior and Human Decision Processes, 35, 124-140.

Becker, G. S. (1968). Crime and punishment: An economic approach. Journal of Political Economy, 76, 169-217.

Caplan, B. (2008). The myth of the rational voter: Why democracies choose bad policies. Princeton University Press.

Frederick, S., Novemsky, N., Wang, J., Dhar, R., \& Nowlis, S. (2009). Opportunity cost neglect. Journal of Consumer Research, 36, 553-561.

Jern, A., Lucas, C. G., \& Kemp, C. (2017). People learn other people's preferences through inverse decision making. Cognition, 168, 263-292.

Kahneman, D., \& Tversky, A. (1979). Prospect theory: An analysis of decision under risk. Econometrica, 47, 263-292.

Kim, H., Schnall, S., Yi, D.-J., \& White, M. P. (2013). Social distance decreases responders' sensitivity to fairness in the Ultimatum Game. Judgment and Decision Making, 8, $632-638$.

Mazar, N., Amir, O., \& Ariely, D. (2008). The dishonesty of honest people: A theory of self-concept maintenance. Journal of Marketing Research, 45, 633-644.

McFadden, D. (1974). Conditional logit analysis of qualitative choice behavior. In P. Zarembka (Ed.), Frontiers in econometrics (pp. 104-142). Academic Press.

Thaler, R. H. (1988). Anomalies: The ultimatum game. The Journal of Economic Perspectives, 2, 195-206.

Thaler, R. H. (1999). Mental accounting matters. Journal of Behavioral Decision Making, 12, 183-206.

Train, K. (2009). Discrete choice models with simulation (Second ed.). Cambridge University Press.

Trope, Y., \& Liberman, N. (2010). Construal-level theory of psychological distance. Psychological Review, 117, 440-463. 